\title{
THE EFFICIENCY EMPLOYMENT OF CLOSE-RANGE PHOTOGRAMMETRY TO MEASURE AND MODEL POTHOLES IN ASPHALT PAVEMENT
}

\author{
AHMED RAMZY JAMEEL ${ }^{*}$ and RAAD AWAD KATTAN ${ }^{* *}$ \\ *Dept. of Civil Engineering, College of Engineering, University of Duhok, Kurdistan Region-Iraq \\ *** Dept. of Surveying Engineering, College of Engineering, University of Duhok, Kurdistan Region-Iraq
}

(Received: October 12, 2020; Accepted for Publication: November 22, 2020)

\begin{abstract}
The objective of this study is to measure and model potholes distress in the pavement road surface, which form a major type among several distresses exist in road networks. In this research close-range photogrammetry is used to represent potholes distress, this approach allows converting images of the studied potholes into a 3-D model. Ground control points (GCPs) have to be distributed uniformly to cover the whole measured area helping to solve analytically for the unknown coordinates of the measured area point cloud and acquiring a georeferenced model with known coordinates.

Agisoft PhotoScan was used for potholes modelling, which is a user-friendly software that allows for 3D modelling, producing digital elevation models, point clouds, and orthomosaic. The Agisoft PhotoScan initial assessment test on a model similar in shape to a real pothole reviles that the best accuracy acquired using 8 GCPs distributed regularly to cover the shape of the pothole have a maximum discrepancy of $2.16 \mathrm{~cm}$ in $Z$ coordinates of one point. The obtained root mean square errors RMS were $\pm 0.79 \pm 0.78$ $\pm 0.67 \mathrm{~cm}$ in $\mathrm{X}, \mathrm{Y}$, and $\mathrm{Z}$ coordinates respectively.

In a real pothole modelling tests on two sites and comparing the model check points coordinates with the ground coordinates, the RMS obtained were, $\pm 0.85, \pm 0.58, \pm 0.44 \mathrm{~cm}$ and $\pm 0.32, \pm 0.27, \pm 0.39 \mathrm{~cm}$ in $X, Y$ and $\mathrm{Z}$ coordinates respectively. Both potholes can be classified as high level potholes as their depths are more than $50 \mathrm{~mm}$ in accordance with known specifications. In volume test carried out on the first model, the Agisoft PhotoScan generated volume was $8413 \mathrm{~cm}^{3}$ confirmed the volume measured with the standard soil test known as sand replacement method which gave a volume of $8311 \mathrm{~cm}^{3}$.
\end{abstract}

KEYWORD: Distress, Close range photogrammetry, 3-D Modelling, GCPs, Agisoft PhotoScan.

\section{INTRODUCTION}

W ell designed and constructed road should survive along its designed life span, reaching 20 years (Adlinge \& Gupta, 2013). Deficiencies in material quality and construction procedures lead to fast deterioration in the pavement surface known as distresses.

Pavement distresses are visible imperfections on the road surface, they are symptoms of the deterioration of pavement structures, and are of many types, potholes which are of bowl-shaped holes of various sizes in the pavement surface, rutting which means a longitudinal surface depression in the wheel path, cracks, and some other types. (Chai, 2005).

Potholes are critical problems for road users throughout the world, which many institutions and several countries collect annual data that potholes cost. For example, in the United States between 2013 and 2018 according to the American Automobile Association around 16 million drivers had affected damage due to potholes. The United Kingdom had estimated the annual pothole's maintenance cost to be more than 12 million pounds. While in India more than 3000 deaths are recorded due to car accidents caused by potholes annually. Due to its sever share in accident and damage extents, potholes in asphalt surface are the main concern in this study.

It can be said that potholes are killing the economy quietly, and it is confirmed that potholes are a global issue that should be addressed. (Paige-Green et al., 2010).

Photogrammetry is being used throughout this study to measure and model the aforementioned pothole's distresses. Photogrammetry can be described as an art of photo taking and measuring significant parameters of the desired object. Previously analog methods were used, by using the stereoscope, two-dimensional pair of photos were converted to three-dimensional view. But nowadays after technological advancement, the analog methods are replaced by digital 
photogrammetry as the whole images processing and measurements can be done digitally. (Tiong et al., 2012).

In this research pairs of overlapping photos are taken to the distressed area. Non vertical images were captured using a non-metric camera. Digital photos are taken from short ranges at different angles and in most cases with $100 \%$ overlapped images. For this reason, the imaging system can be categorized as a closerange photogrammetric system. The main challenging task is providing ground control points (GPCs) in object space.

In this paper digital close-range photogrammetric method is used for pavement distress data collection, because it is a speedy and more flexible method as compared to other traditional distresses measurement methods. Providing a photogrammetric model will facilitate visualizing the distress and provide permanent documentation of the pavement surface condition, which could be referred whenever needed. (Mustaffara et al., 2008).

The aims of this research are to use closerange photogrammetry with non-metric cameras, to make a 3-D model from selecting positions and to extract information such as DEM, orthomosaic, contour map, and volume of the distressed area, and also suitable documentation of the distressed area.

To achieve these aims: a system of measuring ground control points (GCPs) in the object space was designed. Design test models to quantify factors that affect the measuring accuracy such as the distribution of control points and base to depth ratio $\mathrm{B} / \mathrm{D}$ of camera location. And utilize the automatic photogrammetric Agisoft PhotoScan software, for the 3-D distress model.

As a specification guide, study performed under the Strategic Highway Research Program in US limits the maximum size of a surface pothole to an area of $0.93 \mathrm{~m} 2$ and a depth of 15 $\mathrm{cm}$.

In UK, a standard for a pothole specifications were set corresponding to a $50 \mathrm{~mm}$ depth on major roads, $60 \mathrm{~mm}$ on unclassified roads, and $25 \mathrm{~mm}$ for locations where they may be a hazard to pedestrians or cyclists. (Clifton Associates Ltd., 2012).

(Shahin, 2009) classified the levels of potholes severity as low, moderate, and high according to their depths, Table 1.

Table (1): potholes classification according to their severity level. (Shahin, 2009).

\begin{tabular}{cc}
\hline Level & Depth (mm) \\
\hline Low & $<25$ \\
\hline Moderate & $25-50$ \\
\hline High & $>50$ \\
\hline
\end{tabular}

\section{RELATED WORK}

\subsection{Straight-Edge method}

A straight edge is a manual measurement method used for direct measurements of distresses such as rutting distress. A straight ruler with a different length according to the region and country is used. The ruler is mainly used to measure the details of the rutting and corrugation of the pavement surface as shown in (Fig. 1-a). AASHTO was relied on a $1.2 \mathrm{~m}$ straight edge, while a flexible (1.83-3.66) m straight edge was suggested by ASTM, in Sweden and China, Strategic Highway Research Program (SHRP) used a different approach that the minimum length of straight edge should be as wide as the width of the driving lane. The straight edge was placed in the driving lane at positions along the wheel path on the road surface, a measurement was taken in the deepest place in millimeter across the wheel path. (Wang et al., 2017).

Straight edge or the surface Profilograph (Fig.1-b) measurement can provide details on the rutting and corrugation distresses but cannot give details of the small pothole's distress.

\subsection{Photogrammetric Approach}

Chai, (2005) described the automatic digital image processing as a modern technique for analyzing pavement distress. With this method, great regions can be surveyed quickly and efficiently. The consistency, objectivity, and precision of collected data can be greatly improved. Using digital automated image processing classification of all types of cracks including (transverse, longitudinal, and alligator) is implemented, as a result, the intensity of each crack automatically will be estimated and this can be utilized for the severity of pavement distress rating. Development in such techniques allow controlling associated problems with the manual method. Subsequently, the results of such an algorithm about cracking type and its level of severity were at an accuracy of $90 \%$ approximately. 


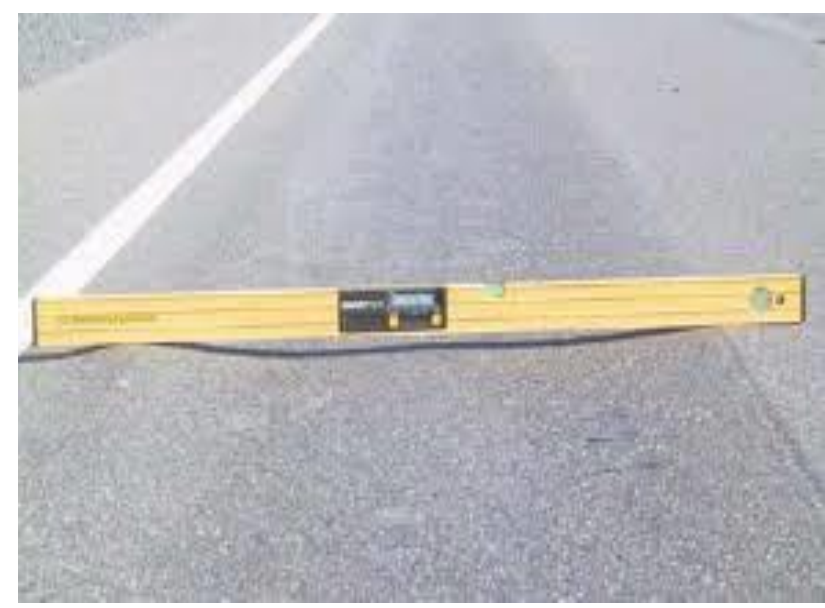

a- Straight-Edge ruler

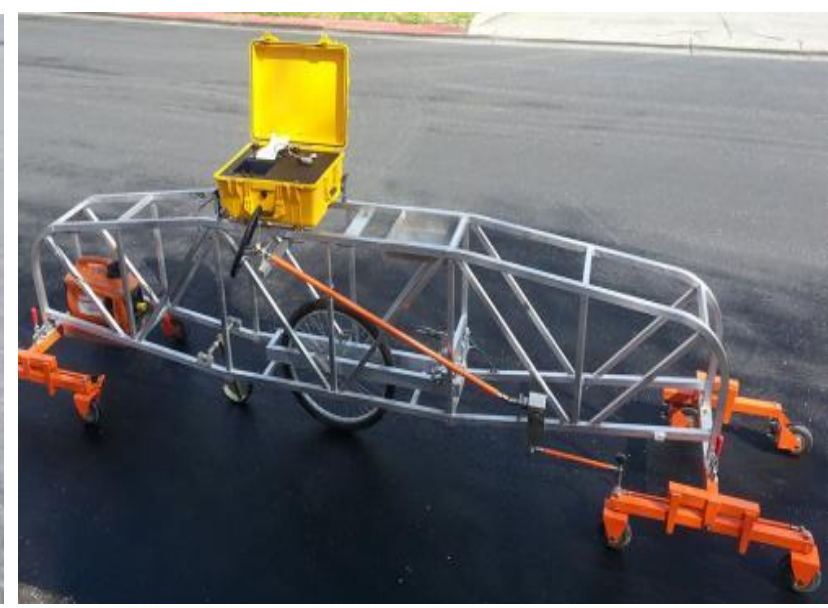

b- Surface Profilograph

Fig. (1): Straight-Edge ruler and Profilograph. (Perera et al., 2005).

Tiong et al., (2012) used Both conventional and digital close-range photogrammetry to evaluate potholes distress detection. 10 potholes samples were taken with various shapes and depths, the depth and diameter of which were measured visually by using the tape and the ruler. After that conducting close-range digital photogrammetry method, two rulers were fixed around the pothole sample as representing the $\mathrm{X}$ $\mathrm{Y}$ axis. Then using a digital camera each pothole sample was captured with 5 images, one for the pothole plan and the remaining images captured with an oblique view. The output is extracting depth and area of potholes using PhotoModeler software as shown in (Fig. 2).

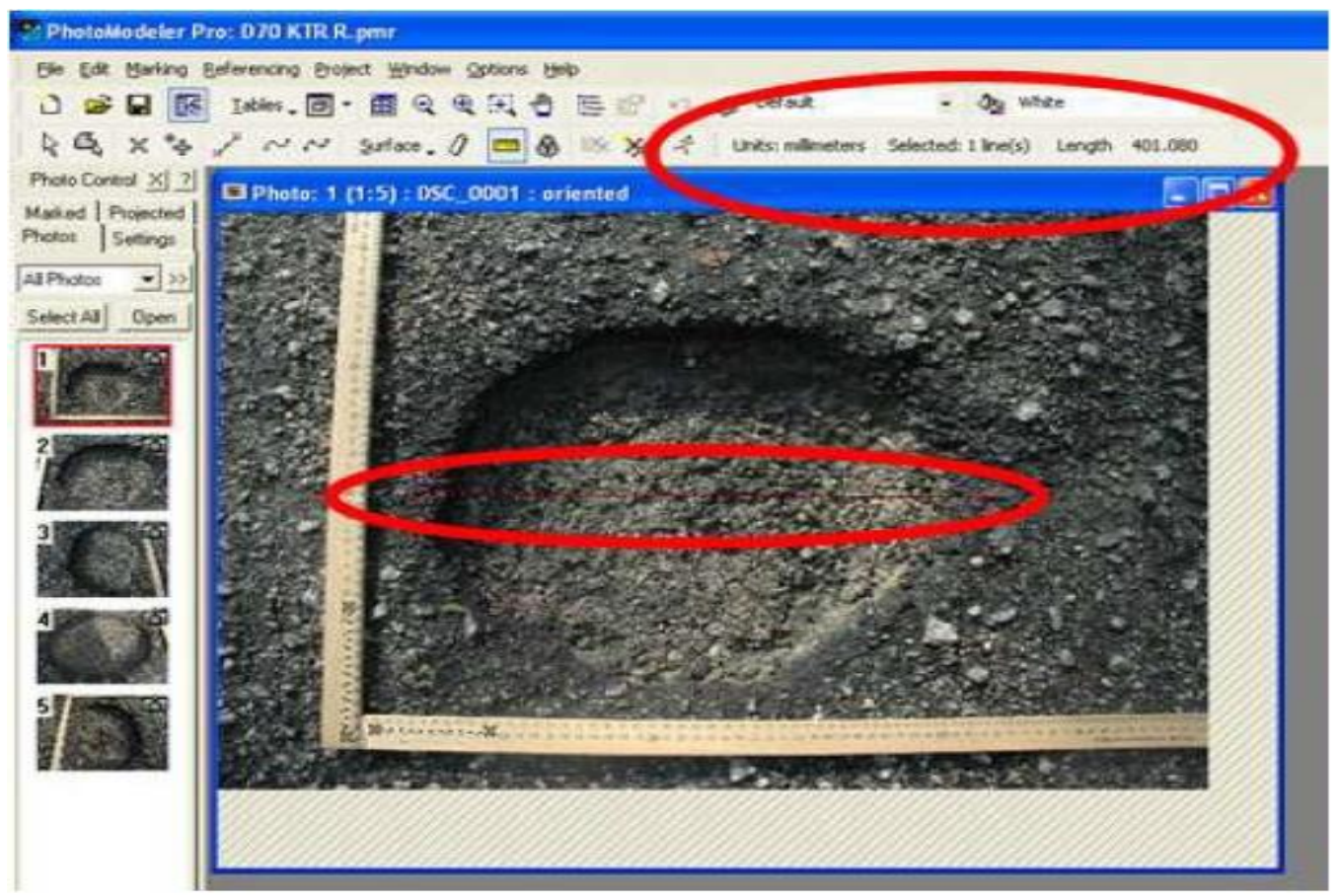

Fig. (2): Extracting measurements by a photogrammetric method.(Tiong et al., 2012).

A distress modelling approach is summarized by: firstly, establishing ground control points (GCPs) around the distressed area using total station device for measurements. Then the height of the photo is fixed to $1 \mathrm{~m}$ according to the designed frame, with camera focal length of (24 mm) Digital Single-Lens Reflex (DSLR) camera. The images of various distressed pavement areas with $60 \%$ overlapping were captured as shown in (Fig. 3), with $(37.5 \mathrm{~cm}$ ) baseline. Software program is used for photogrammetric image processing to evaluate 
distresses of the pavement surface after the ortho-images have been created. Finally, in ortho-rectified measurement window all fundamental measurement that is need to measure such as; area, width, and depth of pavement distresses are available. The outcome of photogrammetric method has been modeled and usually compared with visual inspection, using the highest coefficient of determination

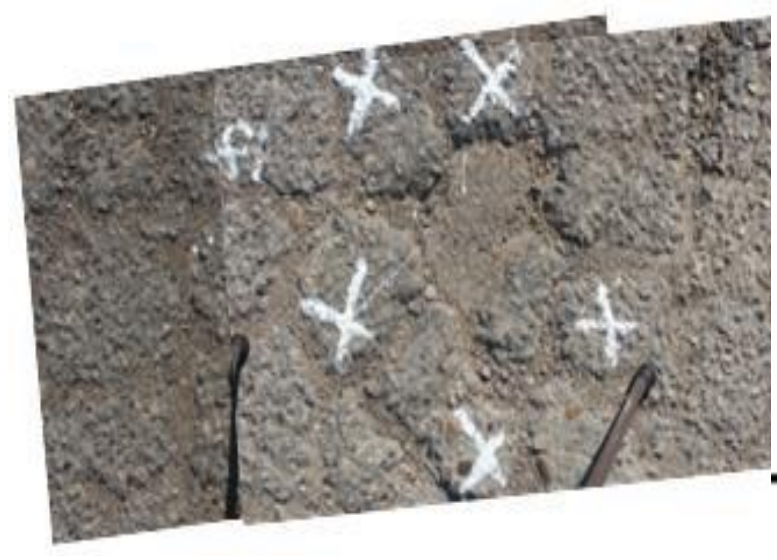

a- Ground control points around distress area.
(R2). In conclusion photogrammetric approach utilization is efficient in pavement distress evaluation with (R2) ranged between $(0.985$ and 0.999 ) in comparison with visual inspection. subsequently the photogrammetric method could provide a permanent documentation of the pavement surface condition, which could be referred whenever needed. (Sarsam et al., 2015).

Fig. (3): GCPs and overlapped image (Sarsam et al., 2015).

Close range terrestrial images or the Unmanned Aerial Vehicle UAV images are used for pavement distress condition assessment. UAV is more flexible, easy to maneuver, and less field work. UAV oblique photos acquired transformed to 3-D model as illustrated in (Fig. 4). Accuracy is affected by factors by the resolution of images, ground control points (GCPs) distribution over the distressed area and some other factors. Pix4Dmaper software is utilized for 3-D model construction, based on this 3-D model road surface identification is done and also pavement distresses are detected automatically, as well as measurements like length, width, and depth of the distressed area are extracted. The output gives precise results as the error is about $1 \mathrm{~cm}$ in height in most distresses. (Tan \& Li, 2019).

The evaluation of pavement conditions is an important part of pavement management. Traditionally, pavement condition data are gathered by human inspectors who walk or drive along the road to assess the distresses and subsequently produce report sheets. This visual survey method is not only time consuming and costly but more importantly it compromises the safety of the field personnel. With an automated digital image processing technique, however, pavement distress analysis can be conducted in a swifter and safer manner. Pavement distresses are captured on images which are later automatically analyzed. Furthermore, the automated method can improve the objectivity, accuracy, and consistency of the distress survey data. This research is aimed at the development of an Automated Pavement Imaging Program (APIP) for evaluating pavement distress condition. The digital image processing program enables longitudinal, transverse, and alligator cracking to be classified. Subsequently, the program will automatically estimate the crack intensity which can be used for rating pavement distress severity. 


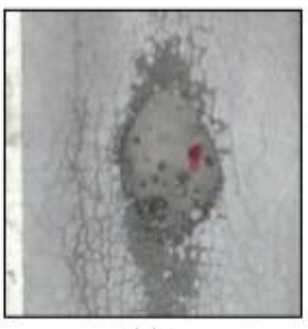

(a)

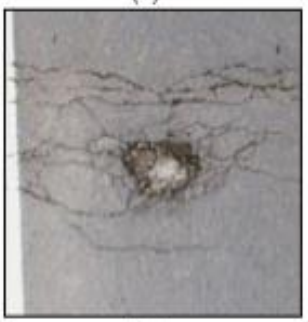

(e)

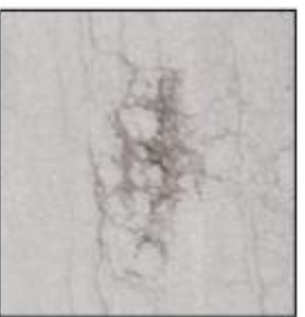

(b)

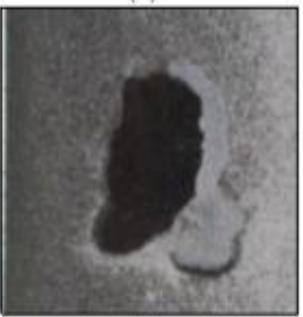

(f)

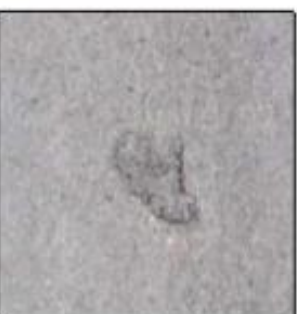

(c)

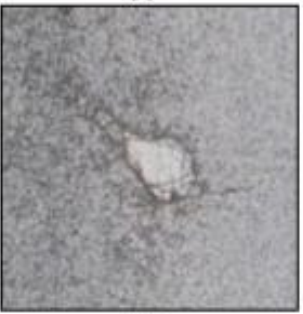

(g)

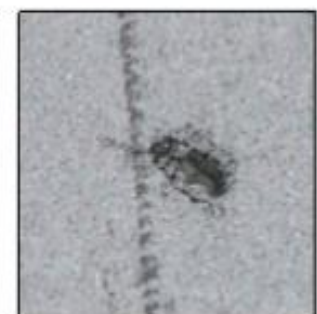

(d)

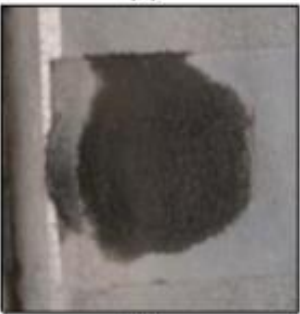

(h)

Fig. (4): UAV Photogrammetry-Based 3-D Road Distress Detection (Tan \& Li, 2019).

Advancement in digital photogrammetric technology creates an opportunity to overcome some problems associated with the manual methods. It can provide a low-cost, near real time geometrical imaging through digital photogrammetry without physically touching the surface being measured. Moreover, digital photogrammetry workstation (DPW) is userfriendly, less tedious and enables surface conditions to be represented as ortho-image, overlay contour with ortho-image, as well as digital elevation model (Fig. 5). The algorithms developed in this study are found to be capable of identifying type of cracking and its severity level with an accuracy of about $90 \%$ when compared to the traditional method. (Mustaffara et al., 2008).
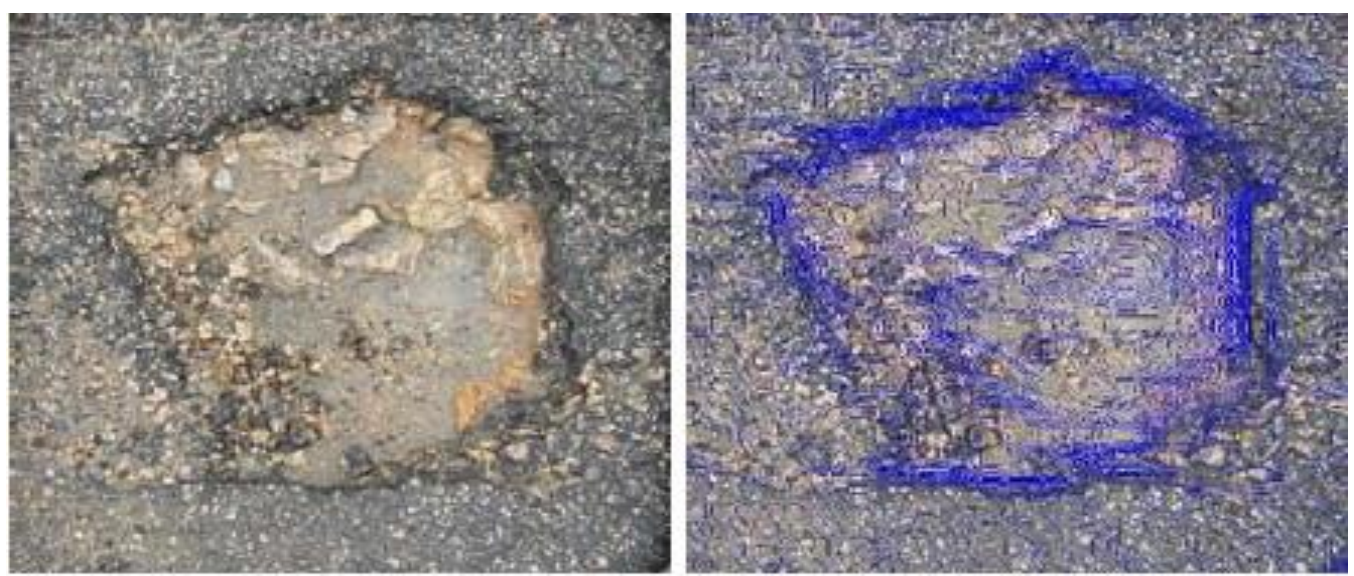

Fig. (5): Ortho-image and contour overlap of pothole. (Mustaffara et al., 2008).

\section{METHODS AND MATERIALS}

\subsection{The Non-Metric Camera}

Non-metric cameras enable the full use of the technical and economic advantages of utilizing photogrammetry in a vast number of applications. Among the advantages of the nonmetric cameras are: 1- the availability for their reasonable prices comparing to metric cameras, and 2- they can be hand-held and directed in any orientation. For this research a DSLR nonmetric camera (Canon EOS Kiss x 3), (Fig. 6) was used. It can generate 4752 x 3168 pixels with a file size of $8.6 \mathrm{MB}$. It has a variable focal length range of (18-55) $\mathrm{mm}$. For this study $\mathrm{f}$ was selected as $18 \mathrm{~mm}$ to ensure a suitable model coverage. 


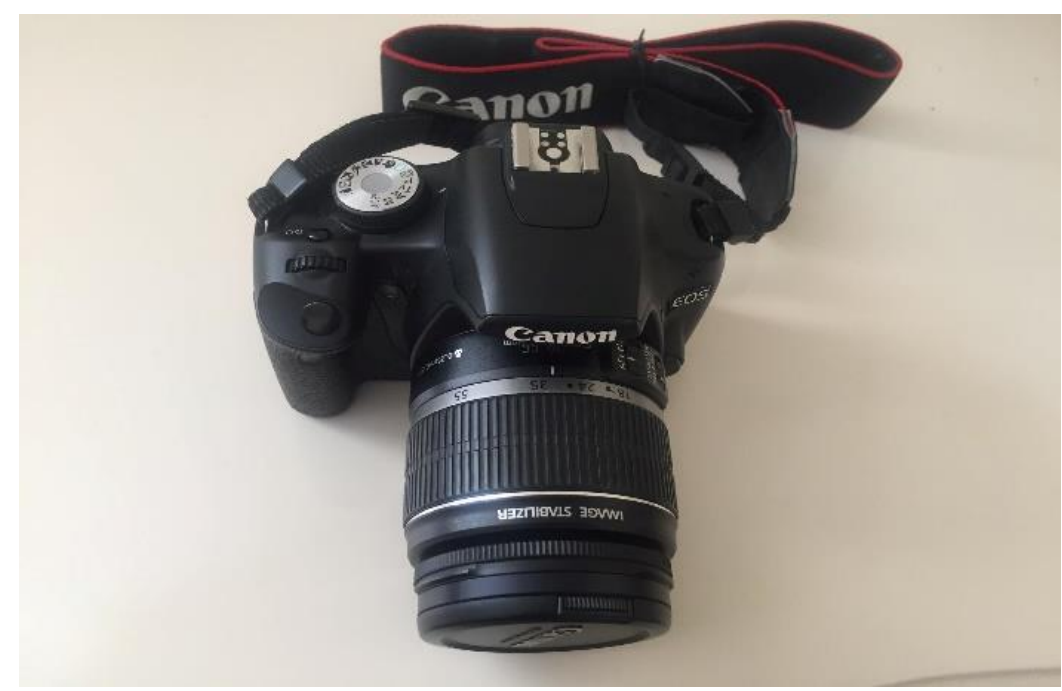

Fig. (6): Canon EOS Kiss x 3 Camera.

\subsection{Analytical Photogrammetric Theories}

Analytical photogrammetry is concerned with establishing the proper mathematical models relating image to object coordinates. The main advantages of analytical photogrammetry are the flexibility of dealing with tilted, vertical, strip, and panoramic photographs. Different scale photographs can be accommodated and there are no limitations on the focal length values (Wolf \& Dewitt, 2000). The second advantage is that the known sources of errors can be mathematically modelled and corrected during the computations. Among these errors are the lens distortion and film deformation. And since the whole process is conducted digitally, different output types can be produced. Among these outputs are the production of orthophoto mosaic, digital elevation model, ground and features 3-D models, line map with contour lines, calculations of earthwork quantities, and many other products.

If the image coordinates of sufficient known control points are measured, then the analytical solution provides the transformation parameters to transfer from image coordinates to space coordinates.

\subsection{Image Distortion}

Several factors affect the quality of the image, causing distortions and displacements of point locations and degrading the accuracy of the measurements. Among these factors are Distortion of the objective lens, Detector array flatness.

In addition to the above factors, there exist several other factors that affect the geometric accuracy of the images such as the movement of the camera during the exposure.

The distortion of the objective lens. and detector array flatness have significant effects on image quality, especially when using non-metric cameras. These cameras are not designed for precision measurements and have low quality lenses. Distortion on the images taken by these cameras appears clearly when photographing a regular grid. Straight lines on the edges of the image appear curved. The distortion will be obvious on wide angle lenses. (Fig. 7) shows two types of distortions that effect the geometric quality of the image. The amount of distortion decreases apparently as we go towards the center of the image. The software used, the PhotoScan is capable of dealing with such errors in the selfcalibration bundle adjustment process.

\subsection{Epipolar Geometry}

The search for the best match between a window in the reference image and a window in the search image can be reduced from a twodimensional search to a one- dimensional search along a line called the epipolar line as shown in (Fig. 8).

Fig. (8) show the epipolar geometry. Points OL and AR represent the optical centers of each image. Each center projects onto a distinct point into the other camera's image plane. These two image points, denoted by $\mathrm{eL}$ and $\mathrm{eR}$, are called epipoles or epipolar points. Both epipoles $\mathrm{eL}$ and $\mathrm{eR}$ in their respective image planes and both optical centers OL and OR lie on a single 3-D line. 


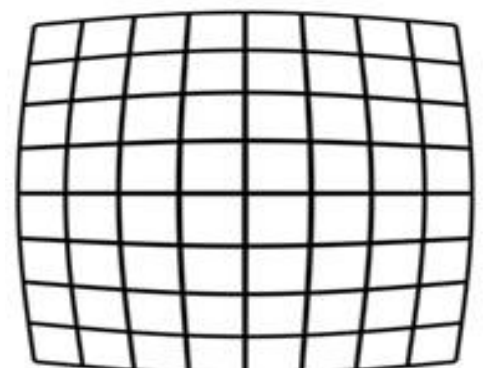

Barrel Distortion

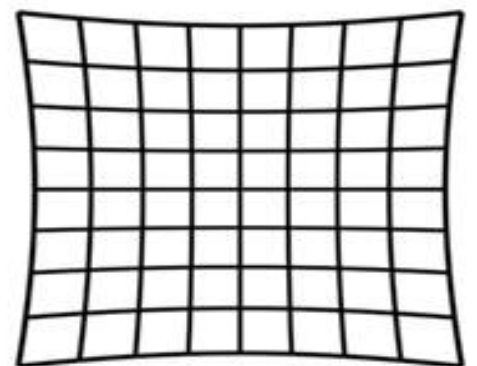

Pincushion Distortion

Fig. (7): Barrel and pincushion image distortion.(Rutty, 2008).

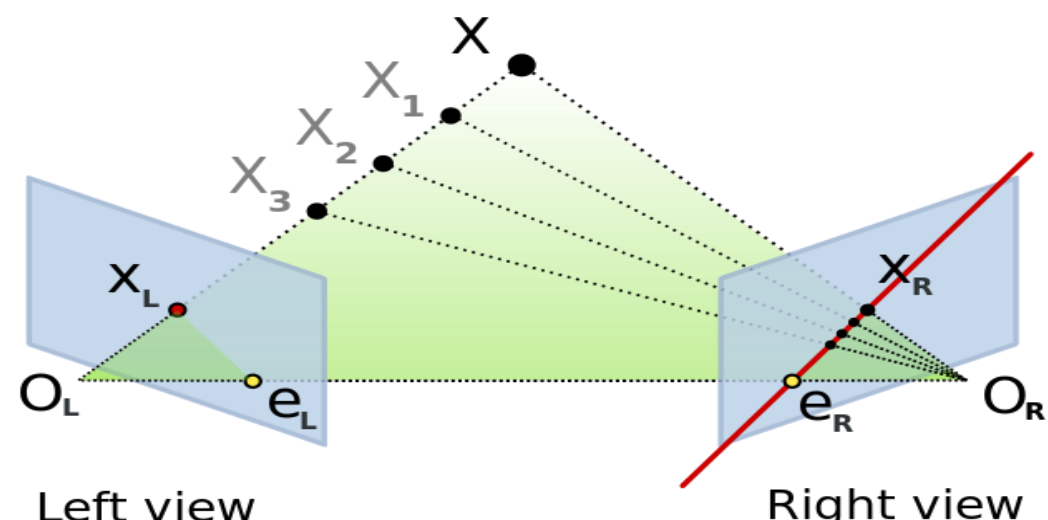

Fig. (8): Epipolar Geometry. (Oh, 2011).

The left camera sees the line OL-X as a point. The right camera sees this line as a line. This line, $(\mathrm{eR}-\mathrm{xR})$ in the right camera is called an epipolar line.

Symmetrically, the line OR-X seen by the right camera as a point is seen as epipolar line $(\mathrm{eL}-\mathrm{xL})$ by the left camera. $(\mathrm{Oh}, 2011)$.
As the position of the 3-D point varies, (Fig. 9), the epipolar planes will rotate about the baseline generating a family of planes. This family of planes is known as epipolar pencil.

Given a pair of images, it is clear that to each point $\mathrm{x}$ in one image there exists a corresponding epipolar line $1^{\prime}$ in the other image.

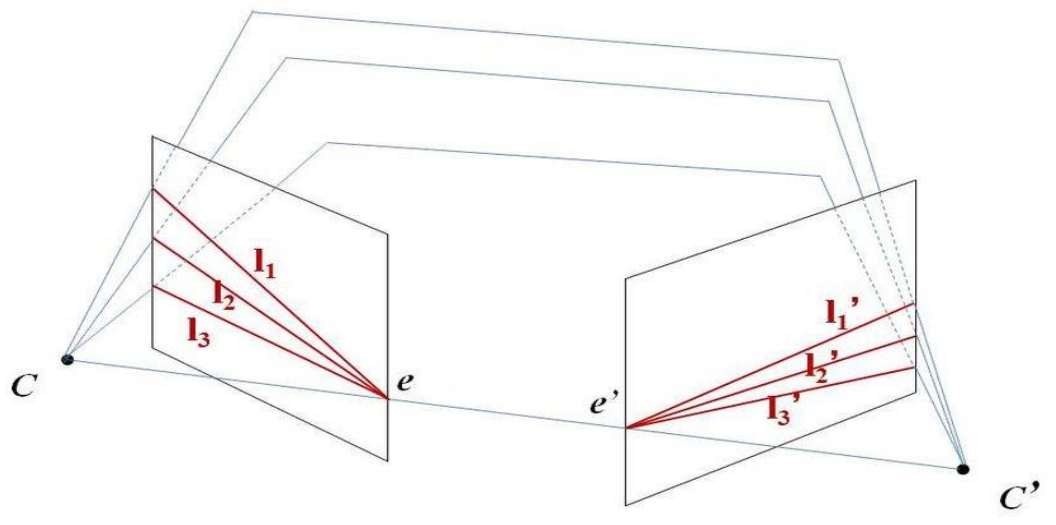

Fig. (9): Epipolar Planes (pencil) Corresponding to Different Object Points.

The epipolar geometry simplifies the search for the corresponding matching point on the second image. So instead of the search being carried out on the whole image, it will be restricted to a single line.

One step in constructing a 3-D model in Agisoft PhotoScan software and after aligning 
the photos is the selection of the control points on the overlapped images. On selecting the point on the first image, the epipolar line will appear passing through the corresponding point on the second image, (Fig. 10). This will indicate the degree of matching accuracy.

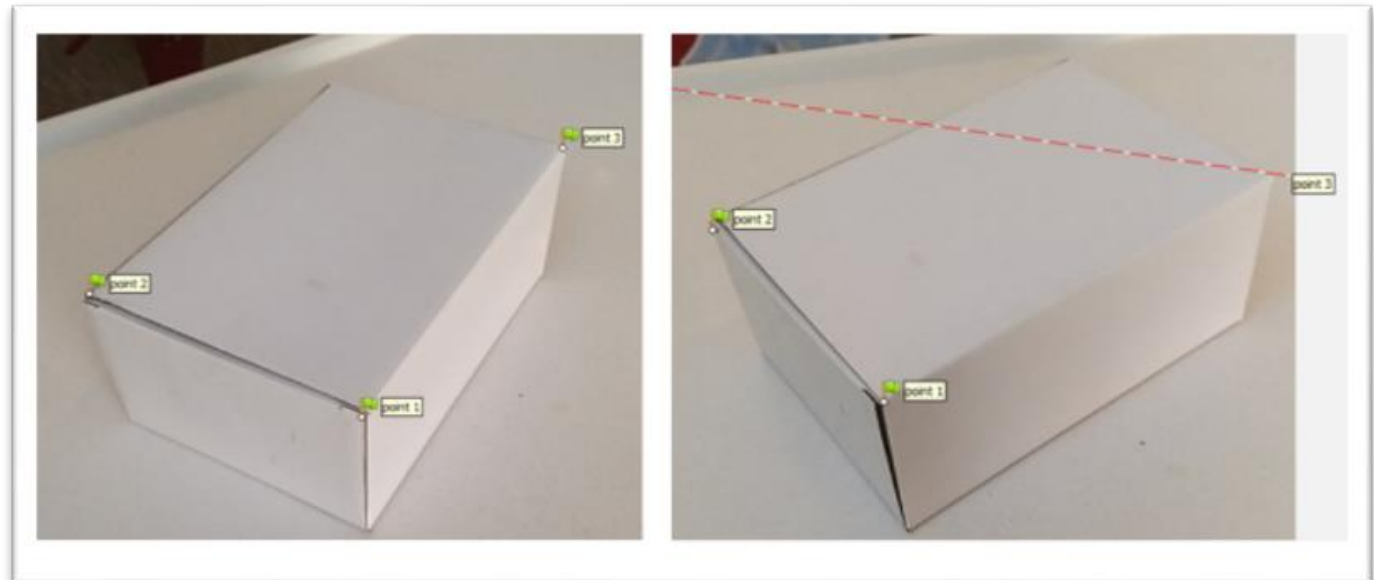

Fig. (10): A point in one image will appear passing through the epipolar line on the second image in Agisoft PhotoScan software.

\subsection{Agisoft PhotoScan in Pavement Distress Modelling}

Agisoft PhotoScan is a three-dimensional scanning software package promoted by Agisoft association in Russia. It is a sophisticated threedimensional modeling package depends on the processing of data from images. It employs the latest 3-D reconstruction technology from multiple views that will process any image captured by a non-metric camera with data ranges from small sculpture to mass data captured from Unmanned Aerial Vehicle (UAV). It enables to process a bundle of photos to generate a high-quality Digital Orthophoto Map (DOM) and Digital Elevation Model (DEM) and finally, 3-D model could be generated which has a lot of applications in various fields. (quan Li et al., 2016).
The theory behind Agisoft PhotoScan software working is using bundle adjustment for the triangulation method. It is also known as an aerotriangulation workflow technique as it depends on the concept that a lot of light rays which are coming from the light source (camera sensor) then a bundle of rays formed whole intersect to create spatial positions. Simultaneous adjustment for bundles from whole involved images is done so that the corresponding light rays intersect at positions of the ground feature. These bundles are adjusted by collinearity equation as an arithmetic model using least-squares solution, the equations are not linear and should be linearized using Taylor's theorem. (Jebur et al., 2018).

Measurement sequence workflow using Agisoft PhotoScan software is presented in the (Fig. 11).

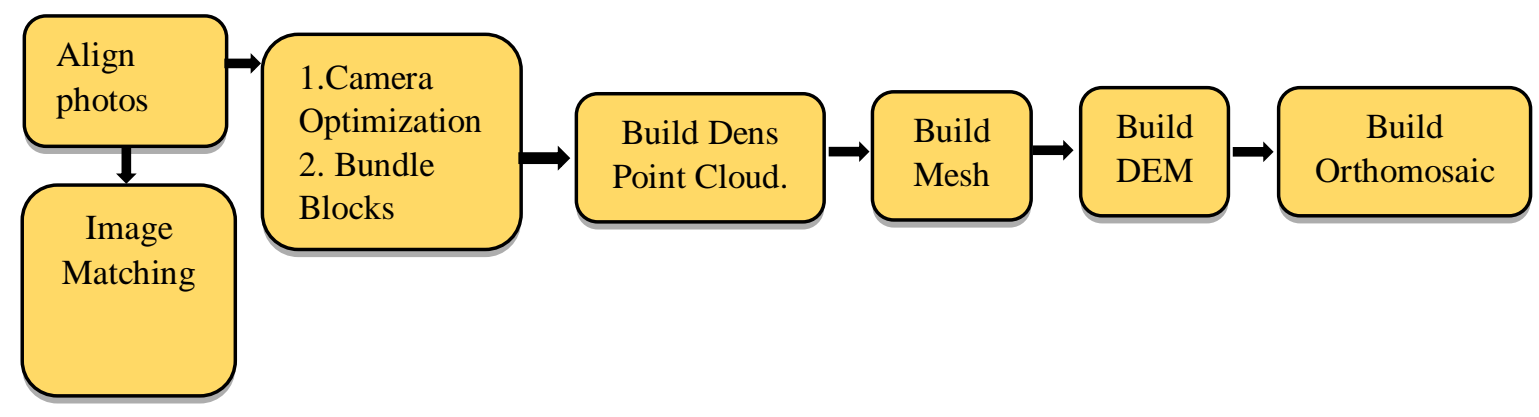

Fig. (11): Agisoft PhotoScan software workflow.

\subsection{Control Point Frame for Pothole distress}

For potholes measurements, a wooden frame of $(40 \times 40) \mathrm{cm}$ was designed and divided with $5 \mathrm{~cm}$ square wire mesh. This frame and the wire mesh make a horizontal control axis. The fieldwork started by placing the frame over the potholes and markers in the form of small colored studs were located beneath the wire 
mesh intersection points. A total of 16 studs were placed and their coordinates are recorded. The $\mathrm{x}$ and $\mathrm{y}$ coordinates of the marker point are found from mesh division and the $\mathrm{z}$ (elevation) is measured using a ruler as shown in (Fig. 12). The $\mathrm{z}$ coordinates of all points are given a (-) negative sign as the mesh surface represents the zero elevation. The non-metric camera was used for taking at least two photos (left, right) for the scene. Some of the studs were used as control and the remaining were used as checking for farther processing in Agisoft PhotoScan methods for 3-D potholes modelling.

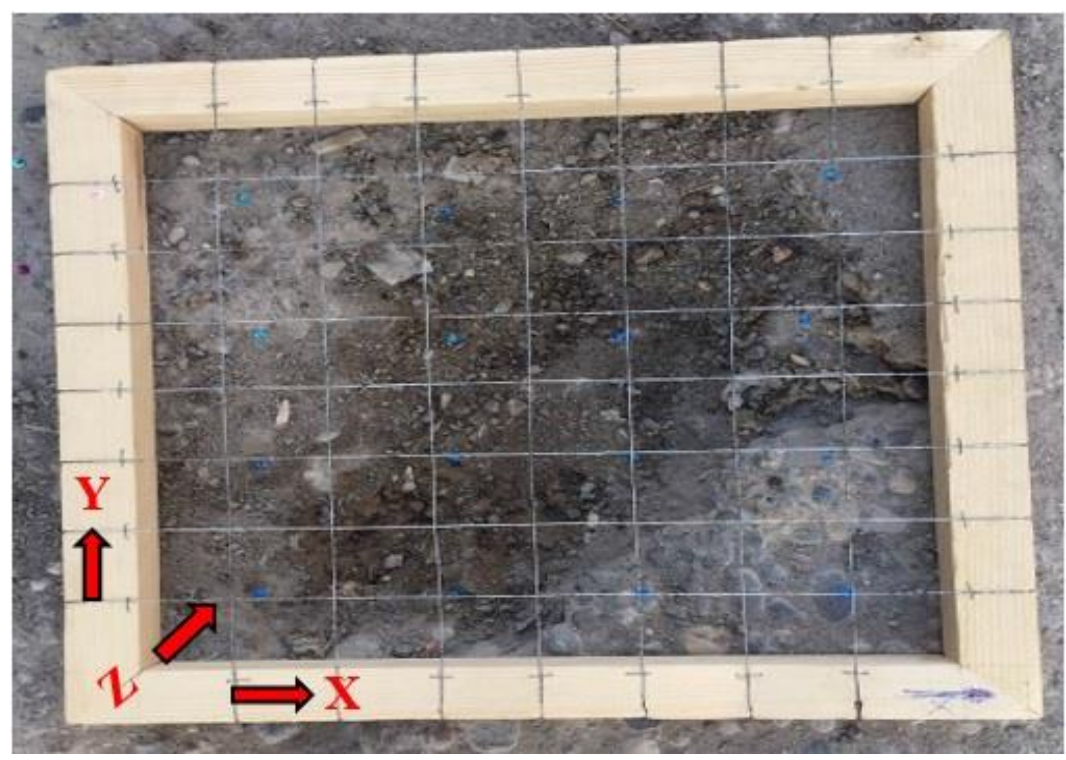

Fig. (12): Control frame for potholes measurements.

\subsection{Volume Measurements}

Measurement of volume of potholes is important to give an extend of potholes size. The surface area does not give an indication of the potholes size even the depth also does not give, because the depth varies from one place to another. In this research, the volume of potholes can be measured by two methods.

The first method is directly from Agisoft PhotoScan as a polygon is drawn around the model and Agisoft can easily measure the volume of the pothole.

The second one is the sand replacement method which is a more accurate method. The procedure of this method is started from a laboratory, unit weight of sand should be determined as the volume of mold and weight of sand is known. Before starting the fieldwork, the sand should be weighted and after the photogrammetric work is ended the sand have to be poured to the pothole till it is filled. The remained sand should be weighted and subtracted from the original weight. The result is the weight of sand that fills the pothole. Sand unit weight is also known using this formula $\left(\gamma_{S}=W / V\right)$ the volume of the pothole can be calculated.

Where $\gamma_{S}$ is unit weight of sand
$\mathrm{W}$ is weight of sand

$\mathrm{V}$ is volume of pothole

\section{RESULTS AND ANALYSIS}

Initial assessment test for Agisoft PhotoScan software was done, and their results were presented and analyzed. After that real pothole on road pavement was also tested and the results are discussed.

\subsection{Initial Assessment Test for Agisoft PhotoScan}

To assess the level of accuracy that can be achieved using images processed by Agisoft PhotoScan a model has been constructed similar to a pothole shape. A plate has been divided into $5 \mathrm{~cm}$ grid and pencils have been glued on the corner of the grid with different elevations ranging between $(6-17.5) \mathrm{cm}$. The tips of the pencils represent the control and check points. The coordinates of control points are listed in the table 2. The pencils were distributed over the grid so that the perimeters of the area have high elevation comparing to the middle of the model. A white cloth sheet covered the pencils and only the tips of the pencils appeared from the cloud, so that these points can be identified and marked on the images. Left and right images were acquired around the model as shown in (Fig. 13). 


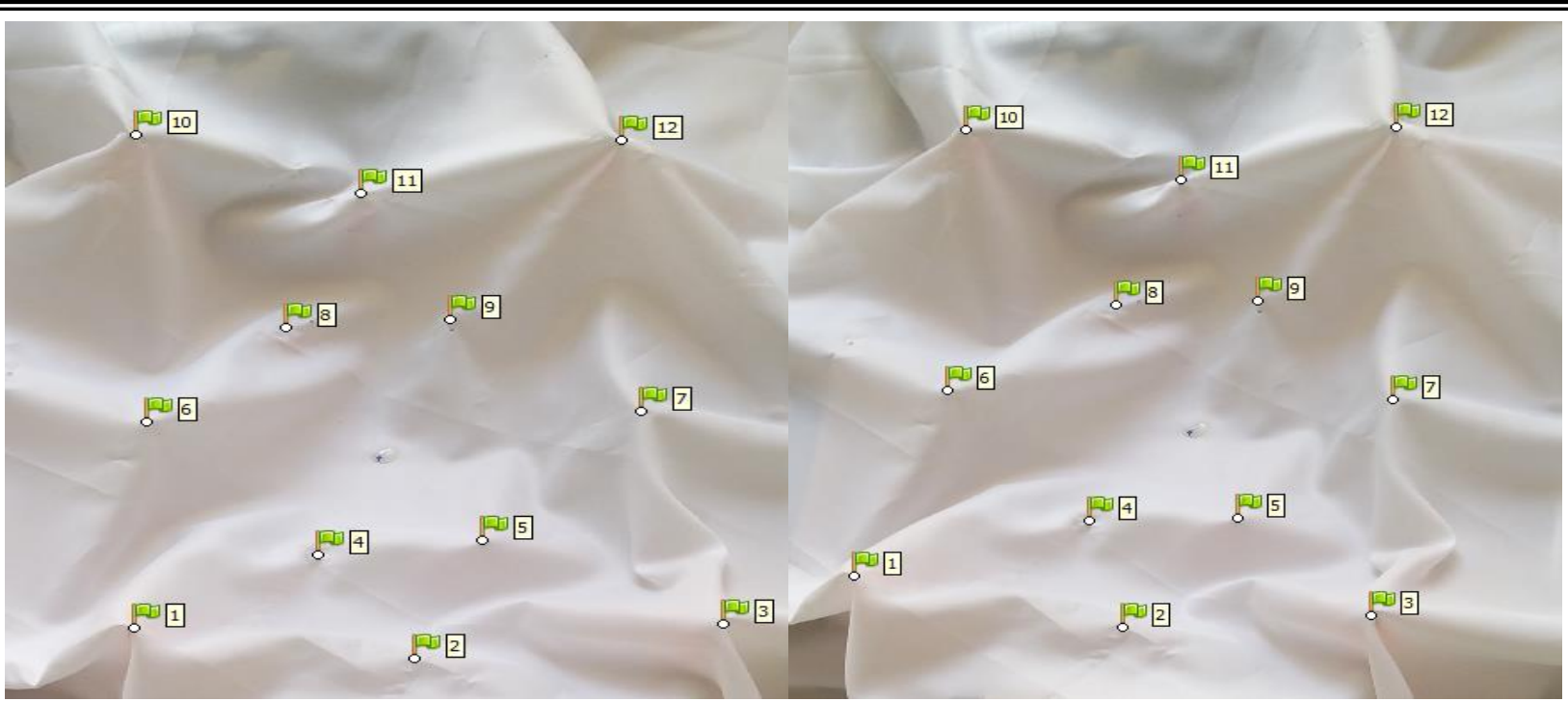

a- Left Image

b- Right Image

Fig. (13): Left and Right images of the test model with 12 control points.

The images were processed using Agisoft PhotoScan software following the procedure given in (Fig. 11). The process was repeated for different cases of control points. The output of the process was an orthophoto and DEM of the area as shown in (Fig. 14).

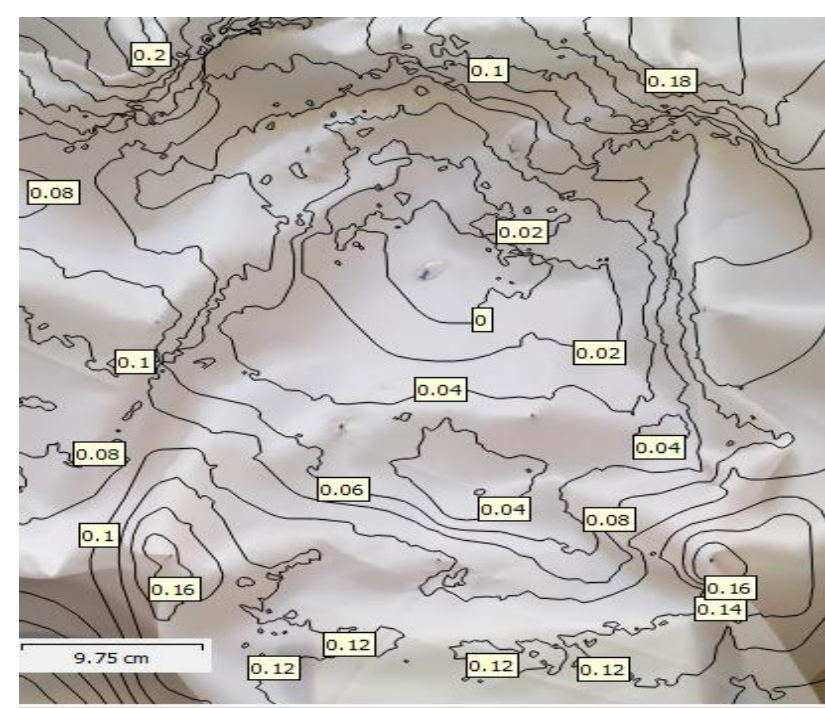

a- Orthophoto from Agisoft

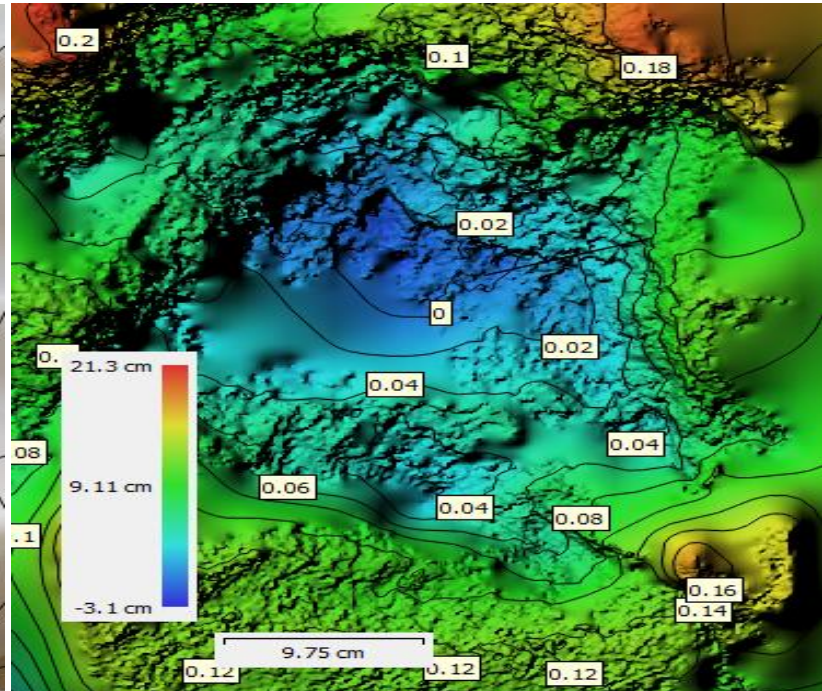

b- DEM from Agisoft

Fig. (14): Orthophoto and DEM of the test model using two images and 12 control points.

The DEM and orthophoto were imported by the AutoCAD civil 3-D. A surface was generated, (Fig. 15) is with contour lines having $2 \mathrm{~cm}$ minor intervals and $10 \mathrm{~cm}$ major intervals. 


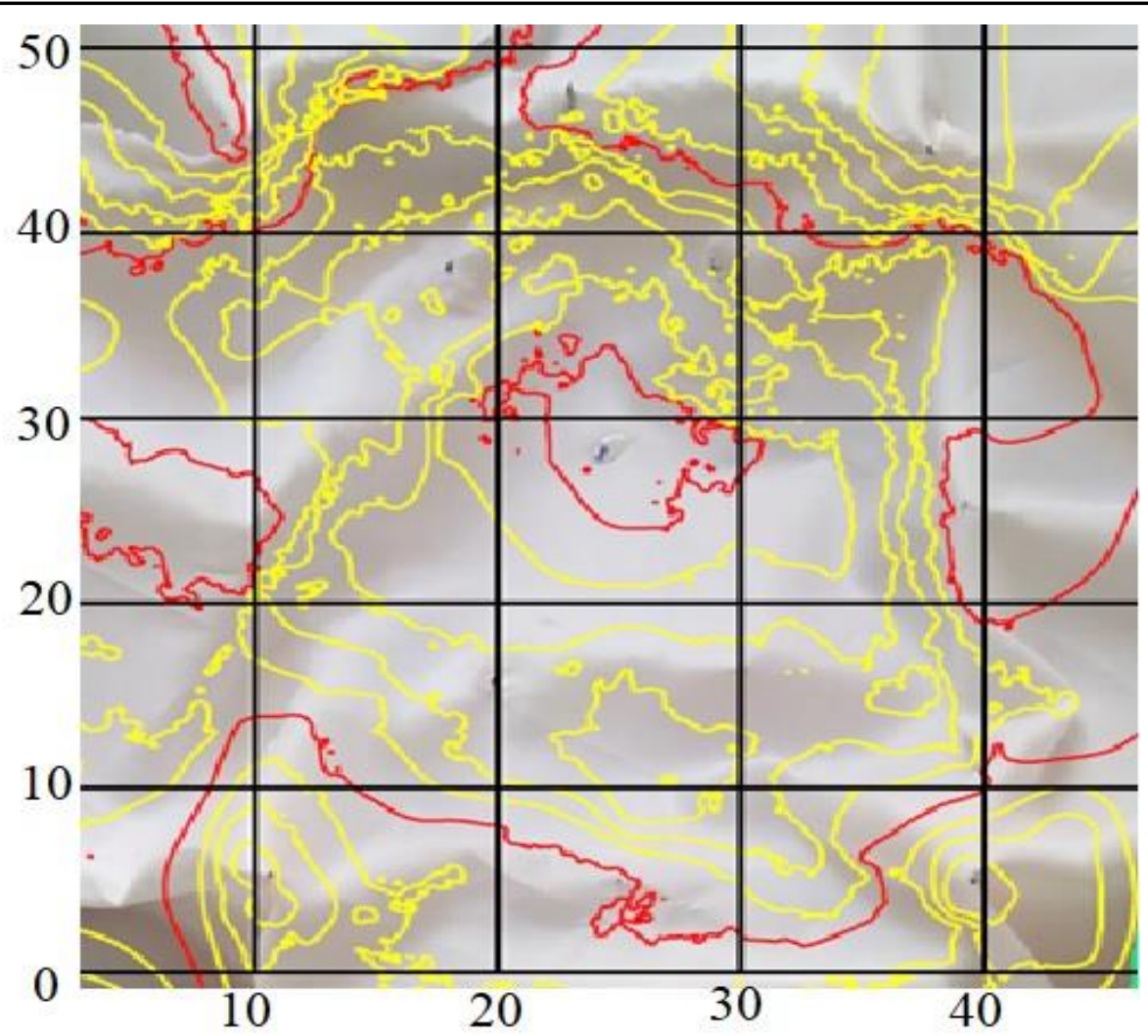

Fig. (15): AutoCAD civil 3-D surface of the test model generated using DEM and orthophoto imported from Agisoft PhotoScan.

Table (2): Measured coordinates of control points of the test model

\begin{tabular}{cccccccc}
\hline points & $\mathbf{X}$ & $\mathbf{Y}$ & $\mathbf{Z}$ & points & $\mathbf{X}$ & $\mathbf{Y}$ & $\mathbf{Z}$ \\
\hline 1 & 10 & 5 & 17.5 & 7 & 40 & 25 & 11 \\
\hline 2 & 25 & 5 & 11 & 8 & 20 & 35 & 6 \\
\hline 3 & 40 & 5 & 17.5 & 9 & 30 & 35 & 6 \\
\hline 4 & 20 & 15 & 6 & 10 & 10 & 45 & 17.5 \\
\hline 5 & 30 & 15 & 6 & 11 & 25 & 45 & 11 \\
\hline 6 & 10 & 25 & 11 & 12 & 40 & 45 & 17.5 \\
\hline
\end{tabular}

As a first test case, 8 images with 12 control points were used and the $\mathrm{x}, \mathrm{y}, \mathrm{z}$ coordinate of the control points were measured from AutoCAD civil 3-D surface and compared with original control points coordinate. Table (3-a) describes the discrepancy with the original coordinates, the results of this case showing a large discrepancy in $\mathrm{Z}$ coordinates reaching $-4.43 \mathrm{~cm}$ in one point. The standard deviation for all points in $X=$ $\pm 0.85 \mathrm{~cm}, Y= \pm 0.96 \mathrm{~cm}$, and $\mathrm{Z}= \pm 1.72 \mathrm{~cm}$. This test reveals that increasing the number of images and control points will not necessary increase the overall accuracy.
The process was repeated using two images (which is more practical for pothole modelling) and 12 control points as illustrated in table (3-b). The discrepancy in this case does not excess $2.06 \mathrm{~cm}$ in $\mathrm{Z}$ coordinates in one point with standard deviation in $X= \pm 0.67 \mathrm{~cm}, Y= \pm 1.25$ $\mathrm{cm}$, and $\mathrm{Z}= \pm 1.14 \mathrm{~cm}$. These are the best accuracy obtained among the other control distributions

Table (3-c) shows the results using 2 images with only 3 control points only (1, 2, and 3$)$. The maximum discrepancy of $4.47 \mathrm{~cm}$ was obtained in $\mathrm{Y}$ coordinates and the standard deviation of $\mathrm{X}= \pm 0.84 \mathrm{~cm} \mathrm{Y}= \pm 1.7 \mathrm{~cm}$, and $\mathrm{Z}= \pm 1.15 \mathrm{~cm}$. 
Obviously the small number of control points and eccentric distribution will not be adequate for high accuracy results.

The same procedure is repeated with 2 images and 5 control points (1-5) and checking the discrepancy of the remaining 7 points, in table (3-d), the maximum discrepancy was of $3.03 \mathrm{~cm}$ in $\mathrm{Y}$ direction and $-2.58 \mathrm{~cm}$ in $\mathrm{Z}$ direction with the standard deviation of $X=$ $\pm 0.81 \mathrm{~cm}, Y= \pm 1.38 \mathrm{~cm}, \mathrm{Z}= \pm 1.21 \mathrm{~cm}$.

Table (3-e) shows the results of the process of using 2 images with 7 control points which are (1-7) the table shows the maximum discrepancy of $3.32 \mathrm{~cm}$ in $\mathrm{Y}$ coordinates and $2.51 \mathrm{~cm}$ in $\mathrm{Z}$ coordinates and standard deviation of $X= \pm 0.93 \mathrm{~cm}, Y= \pm 1.53 \mathrm{~cm}, Z= \pm 1.18 \mathrm{~cm}$.
Using 2 images with 8 uniformly distributed control points gives high accuracy results as shown in table (3-f). The maximum discrepancy is $-2.16 \mathrm{~cm}$ in $\mathrm{Z}$ coordinates and $-1.81 \mathrm{~cm}$ in $\mathrm{X}$ coordinates with standard deviation of $X= \pm 0.79$ $\mathrm{cm}, \mathrm{Y}= \pm 0.78 \mathrm{~cm}$, and $\mathrm{Z}= \pm 0.67 \mathrm{~cm}$.

That is why in the field potholes tests GCPs are uniformly distributed over the distressed area rather than clustering them in one side of the model.

\begin{tabular}{cccc}
\hline \multicolumn{4}{c}{ Discrepancy } \\
\hline points & $X(\mathrm{~cm})$ & $Y(\mathrm{~cm})$ & $Z(\mathrm{~cm})$ \\
\hline $1 \mathrm{c}$ & -0.38 & 1.23 & 0.55 \\
\hline $2 \mathrm{c}$ & -0.02 & -0.46 & -0.12 \\
\hline 3c & 0.38 & 1.12 & -3.97 \\
\hline $4 \mathrm{c}$ & 0.02 & -0.59 & -0.29 \\
\hline $5 \mathrm{c}$ & 0.64 & 0.29 & -0.11 \\
\hline 6c & 0.02 & -0.82 & 0.56 \\
\hline $7 \mathrm{c}$ & -0.17 & -0.43 & -1.57 \\
\hline 8c & -0.72 & 0.56 & -0.47 \\
\hline 9c & -0.47 & 0.11 & -1.11 \\
\hline $10 \mathrm{c}$ & -1.46 & -0.4 & -3.31 \\
\hline $11 \mathrm{c}$ & -1.59 & -1.14 & -1.72 \\
\hline $12 \mathrm{c}$ & -2.2 & -2.19 & -4.43 \\
\hline$\sigma$ & \pm 0.85 & \pm 0.96 & \pm 1.72 \\
\hline
\end{tabular}

Table (3): Agisoft PhotoScan Initial Assessment model test results summery.

Table (3-a) 8 images with 12 control points.

Table (3-b) 2 images with 12 control points

Discrepancy

\begin{tabular}{cccc}
\hline Points & $X(\mathrm{~cm})$ & $Y(\mathrm{~cm})$ & $Z(\mathrm{~cm})$ \\
\hline 1c & 0.45 & 1.41 & -2.23 \\
\hline 2c & -0.14 & -0.41 & 0.15 \\
\hline 3c & -0.99 & -0.5 & 1.05 \\
\hline 4c & 0.36 & 0.04 & -0.8 \\
\hline $5 \mathrm{c}$ & 0.28 & 0.59 & -0.43 \\
\hline 6c & 0.63 & -0.95 & -0.07 \\
\hline 7c & -0.24 & -1.12 & -0.02 \\
\hline 8c & -0.74 & 2.12 & -2.11 \\
\hline 9c & 0.01 & 1.83 & -1.6 \\
\hline $10 \mathrm{c}$ & 0.89 & 0.04 & 0.25 \\
\hline $11 \mathrm{c}$ & -0.56 & 1.92 & -2.06 \\
\hline $12 \mathrm{c}$ & -1.23 & -1.34 & 0.64 \\
\hline$\sigma$ & \pm 0.67 & \pm 1.25 & \pm 1.14 \\
\hline
\end{tabular}


Table (3-c) 2 images with 3 control points.

\begin{tabular}{|c|c|c|c|}
\hline \multirow[b]{2}{*}{ points } & \multicolumn{3}{|c|}{ Discrepancy } \\
\hline & $X(\mathrm{~cm})$ & $\mathrm{Y}(\mathrm{cm})$ & $\mathrm{Z}(\mathrm{cm})$ \\
\hline 1c & 0.08 & 0.41 & -1.07 \\
\hline $2 c$ & -0.01 & -0.11 & -0.88 \\
\hline $3 c$ & -0.21 & 0.02 & 0.6 \\
\hline 4 & -0.19 & 0.8 & -1.57 \\
\hline 5 & 0.29 & 1.83 & -1.1 \\
\hline 6 & -0.5 & -0.15 & -0.24 \\
\hline 7 & -0.47 & 0.88 & -0.47 \\
\hline 8 & -2.01 & 4.14 & -2.03 \\
\hline 9 & -0.86 & 3.94 & -1.22 \\
\hline 10 & -1.01 & 1.44 & 1.14 \\
\hline 11 & -2.01 & 4.47 & -1.4 \\
\hline 12 & -1.98 & 1.03 & 1.73 \\
\hline$\sigma$ & \pm 0.84 & \pm 1.70 & \pm 1.15 \\
\hline
\end{tabular}

Table (3-e) 2 images with 7 control points.

\begin{tabular}{|c|c|c|c|}
\hline \multirow[b]{2}{*}{ Points } & \multicolumn{3}{|c|}{ Discrepancy } \\
\hline & $\mathrm{X}(\mathrm{cm})$ & $\mathrm{Y}(\mathrm{cm})$ & $\mathrm{Z}(\mathrm{cm})$ \\
\hline $1 \mathrm{c}$ & 0.6 & 0.23 & -0.83 \\
\hline $2 c$ & -0.07 & -0.05 & -0.67 \\
\hline $3 c$ & -0.59 & -0.04 & 0.24 \\
\hline $4 c$ & -0.19 & 0.7 & -0.92 \\
\hline $5 c$ & -0.14 & 1.54 & -0.6 \\
\hline $6 c$ & -0.13 & -0.82 & 0.7 \\
\hline $7 c$ & -0.76 & 0.35 & 0.1 \\
\hline 8 & -2.07 & 3.32 & -0.73 \\
\hline 9 & -1.41 & 3.32 & -0.65 \\
\hline 10 & -0.73 & 0.05 & 2.51 \\
\hline 11 & -2.03 & 3.23 & -0.18 \\
\hline 12 & -2.31 & -0.48 & 2.27 \\
\hline$\sigma$ & \pm 0.93 & \pm 1.53 & \pm 1.18 \\
\hline
\end{tabular}

Table (3-d) 2 images with 5 control points.

\begin{tabular}{cccc}
\hline \multicolumn{3}{c}{ Discrepancy } \\
\hline points & $X(\mathrm{~cm})$ & $Y(\mathrm{~cm})$ & $Z(\mathrm{~cm})$ \\
\hline $1 \mathrm{c}$ & 0.45 & 1.02 & -2.58 \\
\hline $2 \mathrm{c}$ & -0.16 & -0.36 & -0.37 \\
\hline $3 \mathrm{c}$ & -0.79 & -0.38 & 0.42 \\
\hline $4 \mathrm{c}$ & -0.05 & 0.4 & -1.12 \\
\hline $5 \mathrm{c}$ & -0.07 & 0.97 & -0.54 \\
\hline 6 & 0.34 & -1.03 & 0.31 \\
\hline 7 & -0.88 & -0.64 & -0.2 \\
\hline 8 & -1.56 & 2.47 & -1.23 \\
\hline 9 & -1.04 & 3.03 & -1.73 \\
\hline 10 & -0.02 & -0.43 & 1.6 \\
\hline 11 & -1.55 & 1.9 & -0.81 \\
\hline 12 & -2.04 & -0.93 & 1.36 \\
\hline$\sigma$ & \pm 0.81 & \pm 1.38 & \pm 1.21 \\
\hline & & &
\end{tabular}

Table (3-f) 2 images with 8 uniformly distributed control points.

\begin{tabular}{|c|c|c|c|}
\hline \multirow[b]{2}{*}{ points } & \multicolumn{3}{|c|}{ Discrepancy } \\
\hline & $X(\mathrm{~cm})$ & $Y(\mathrm{~cm})$ & $\mathrm{Z}(\mathrm{cm})$ \\
\hline $1 c$ & -0.35 & 1.33 & -0.85 \\
\hline 2c & 0.05 & -0.49 & -0.48 \\
\hline $3 c$ & 0.78 & 0.3 & -0.31 \\
\hline 4 & 0.28 & -0.4 & -0.58 \\
\hline 5 & 0.53 & 0.47 & -0.34 \\
\hline $6 c$ & 0.36 & -0.69 & 0.27 \\
\hline $7 c$ & 0.29 & -0.56 & -0.22 \\
\hline 8 & -0.57 & 0.57 & -0.86 \\
\hline 9 & 0.21 & 0.57 & 0.29 \\
\hline $10 c$ & -0.31 & 0.01 & -0.69 \\
\hline $11 \mathrm{c}$ & -1.48 & -0.8 & -1.36 \\
\hline $12 \mathrm{c}$ & -1.81 & -1.5 & -2.16 \\
\hline$\sigma$ & \pm 0.79 & \pm 0.78 & \pm 0.67 \\
\hline
\end{tabular}




\subsection{Pothole Modelling: Test-One}

In a field measurement, the control frame is placed over the selected pothole and the 16 stud marks are placed on the surface beneath the mesh at the exact position in $\mathrm{X}$ and $\mathrm{Y}$. The depth is measured from the mesh surface to the studs and recorded as negative. Among the 16 control points distributed over the pothole 10 were used as control points for processing. Points $(1,4,6$, $7,9,10,11,12,14$, and 15) were selected to cover uniformly the pothole area and to follow its shape. The remaining 6 were used as check points. For the Agisoft processing the left and right images as shown in (Fig. 16) are added to the software and using the 10 control points as explained in (Fig. 10). After that, a DEM and orthophoto mosaic were produced and imported by the AutoCAD civil 3-D to generate counter line surface superimposed on the orthophoto mosaic. $\mathrm{B} / \mathrm{H}=1$ and focal length is $18 \mathrm{~mm}$, Table 4 shows the maximum discrepancy $1.53 \mathrm{~cm}$ in $\mathrm{X}$ coordinates, $-1.11 \mathrm{~cm}$ in $\mathrm{Y}$ coordinates, and $1.1 \mathrm{~cm}$ in $\mathrm{Z}$ coordinates and with a standard deviation of $X= \pm 0.85 \mathrm{~cm}, Y= \pm 0.58 \mathrm{~cm}$, and $Z=$ $\pm 0.44 \mathrm{~cm}$. Also, a pothole volume measurement and diagonal profile from point $(0,0)$ to $(40,40)$ $\mathrm{cm}$ can be obtained directly from Agisoft PhotoScan. For volume comparison, a sand replacement test was also done and the result shows a close agreement with that of Agisoft PhotoScan.

(Fig. 17-a) shows DEM extracted from Agisoft PhotoScan software with a $1 \mathrm{~cm}$ counter line interval. While (Fig. 17-b) is the Diagonal profile from point $(0,0)$ to $(40,40) \mathrm{cm}$ to define the pothole shape generated by Agisoft PhotoScan.

(Fig. 18) is Counter line surface from Agisoft PhotoScan software matched with orthomosaic and imported by the AutoCAD civil 3-D with 1 $\mathrm{cm}$ counter line interval.

The volume of pothole from Agisoft PhotoScan was $8413 \mathrm{~cm} 3$, for checking volume is determined by sand replacement test and it gives $8311 \mathrm{~cm} 3$.

\section{Sand Replacement Measurements}

Volume of mold $=944 \mathrm{~cm}^{3}$

Weight of mold $=3704 \mathrm{~g}$

Weight of mold + sand $=5035 \mathrm{~g}$

Weight of sand in mold $=5035-3704$

$$
\begin{aligned}
& =1331 \mathrm{~g} \\
& \gamma_{\text {sand }}=\frac{W}{V}=\frac{1331}{944}=1.41 \mathrm{~g} / \mathrm{cm}^{3} \\
& W_{\text {sand }} \text { filled the pothole }=14927-3208 \\
& V_{\text {pothole }}=\frac{\underset{W}{=} 11719 \mathrm{~g}}{Y_{\text {sand }}}=\frac{11719}{1.41}=8311 \mathrm{~cm}^{3}
\end{aligned}
$$

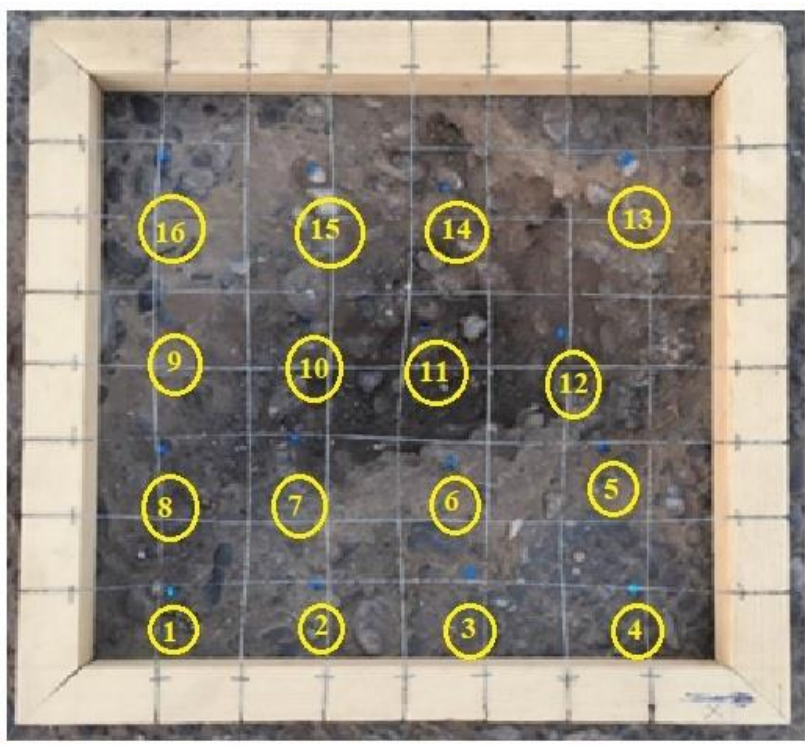

a- Left Image

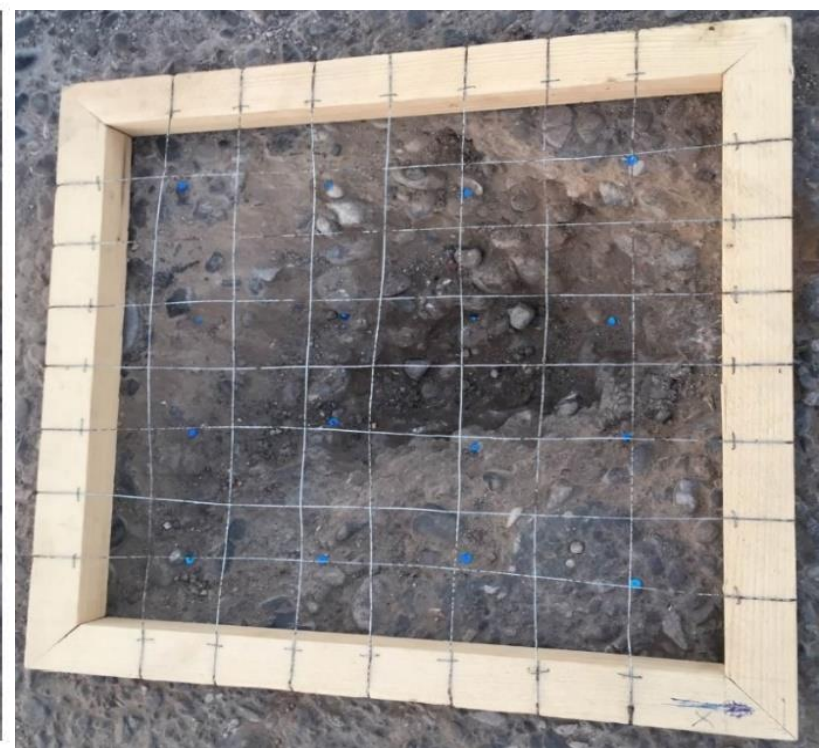

b- Right Image

Fig. (16): Test One left and right images. 


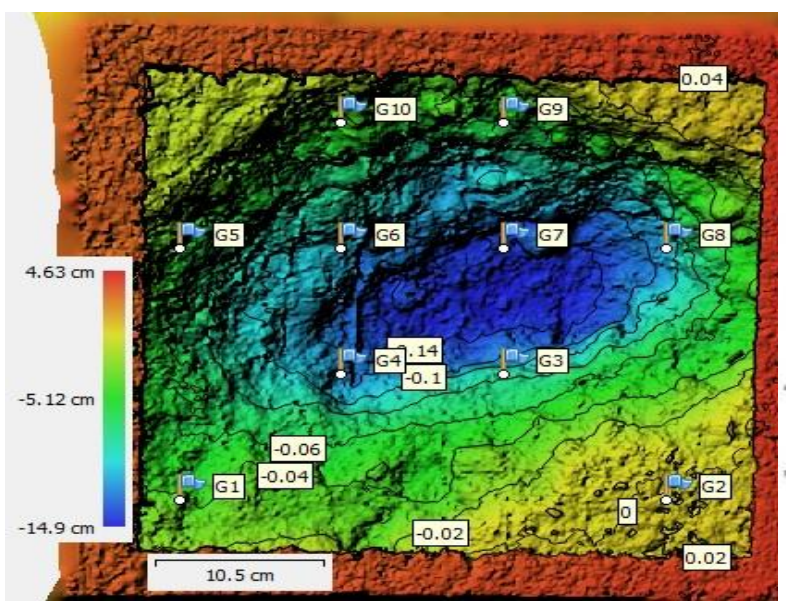

a- DEM extracted from Agisoft PhotoScan.

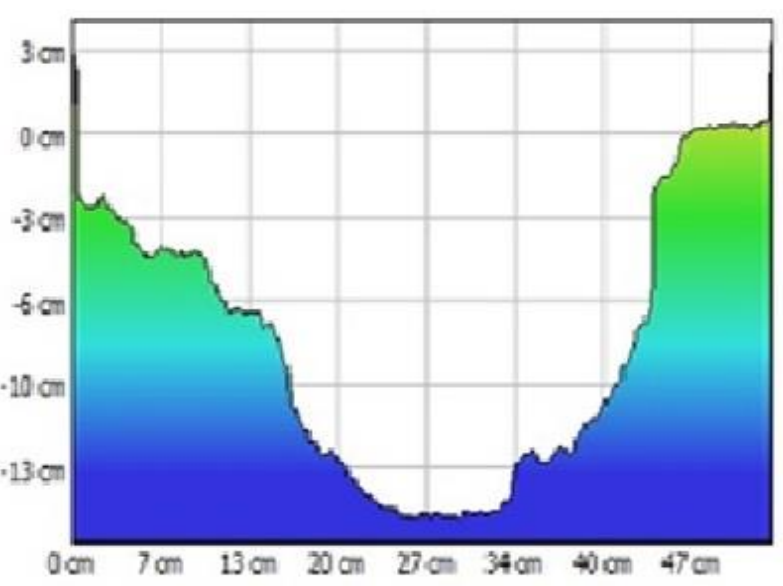

b- Diagonal profile from point $(0,0)$ to $(40,40) \mathrm{cm}$.

Fig. (17): DEM and Profile extracted from Agisoft PhotoScan software.

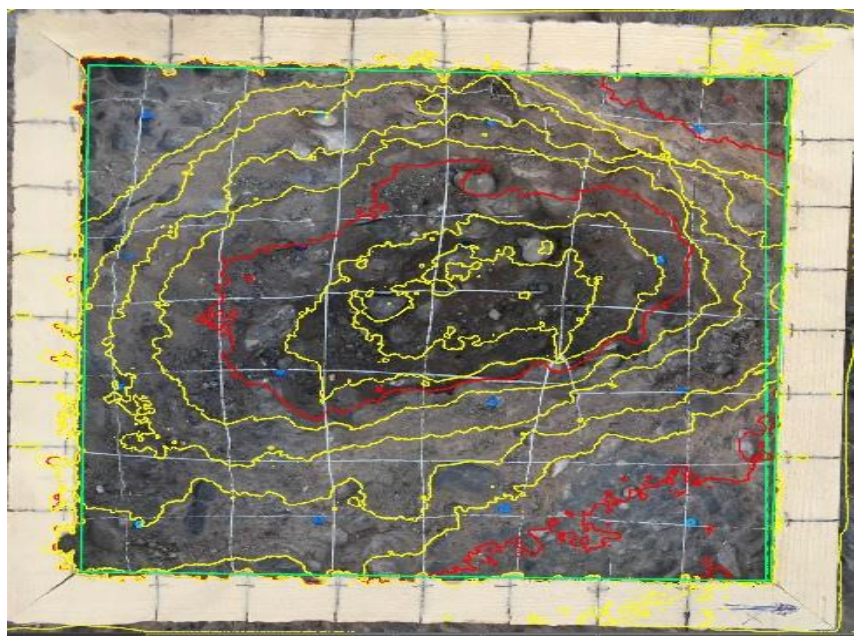

Fig. (18): Counter line surface superimposed by orthophoto mosaic.

Table (4): Discrepancy results of Test 1 using 2 images with 10 uniformly distributed GCPs.

Discrepancy

Discrepancy

\begin{tabular}{cccccccc}
\hline Points & $X(\mathrm{~cm})$ & $Y(\mathrm{~cm})$ & $Z(\mathrm{~cm})$ & Points & $X(\mathrm{~cm})$ & $Y(\mathrm{~cm})$ & $Z(\mathrm{~cm})$ \\
\hline $1 \mathrm{C}$ & 1.1 & -0.21 & -0.3 & $9 \mathrm{C}$ & 0.51 & -0.18 & -0.1 \\
\hline 2 & 0.74 & 0.11 & 0.2 & $10 \mathrm{C}$ & -0.19 & 0.49 & 0 \\
\hline 3 & 0.73 & 0.93 & 0.1 & $11 \mathrm{C}$ & -1.37 & 0.57 & -0.2 \\
\hline $4 \mathrm{C}$ & 0.71 & -0.13 & 0 & $12 \mathrm{C}$ & -0.89 & -0.5 & 0.2 \\
\hline 5 & 0.24 & -0.26 & 1.1 & 13 & 1.2 & -0.72 & 0.3 \\
\hline $6 \mathrm{C}$ & 0.09 & -1.11 & -0.1 & $14 \mathrm{C}$ & 0.3 & -0.2 & 0.4 \\
\hline $7 \mathrm{C}$ & -1.28 & 1.05 & -0.8 & $15 \mathrm{C}$ & 0.88 & 0.47 & -0.4 \\
\hline 8 & 0.02 & 0.06 & -0.4 & 16 & 1.53 & 0.36 & -0.5 \\
\hline & & & & $\sigma$ & \pm 0.85 & \pm 0.58 & \pm 0.44 \\
\hline
\end{tabular}

\subsection{Pothole Modelling: Test-Two}

In a second site, the same procedure followed for test one was repeated for test two except that control points $(1,4,6,7,11,12,14$,
15) were selected to cover uniformly the pothole area and to follow the shape of pothole, the remaining 8 were used as check points, (Fig. 19). 


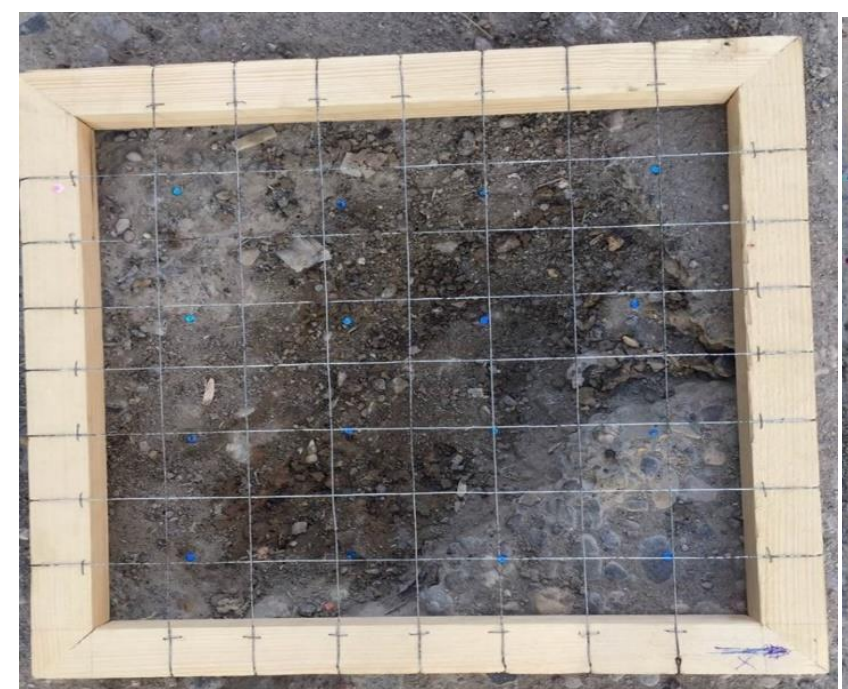

a- Left Image

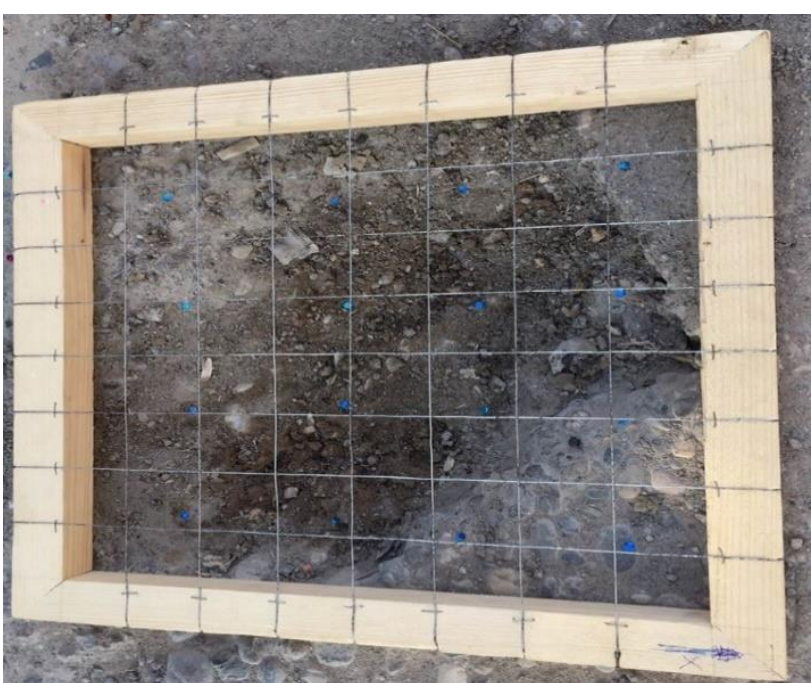

b- Right Image

Fig. (19): Test Two left and right images.

Fig. 20-a) shows DEM extracted from Agisoft PhotoScan software with a $1 \mathrm{~cm}$ counter line interval. While (Fig. 20-b) is the Diagonal profile from point $(0,0)$ to $(40,40) \mathrm{cm}$ to define the pothole shape generated by Agisoft PhotoScan.

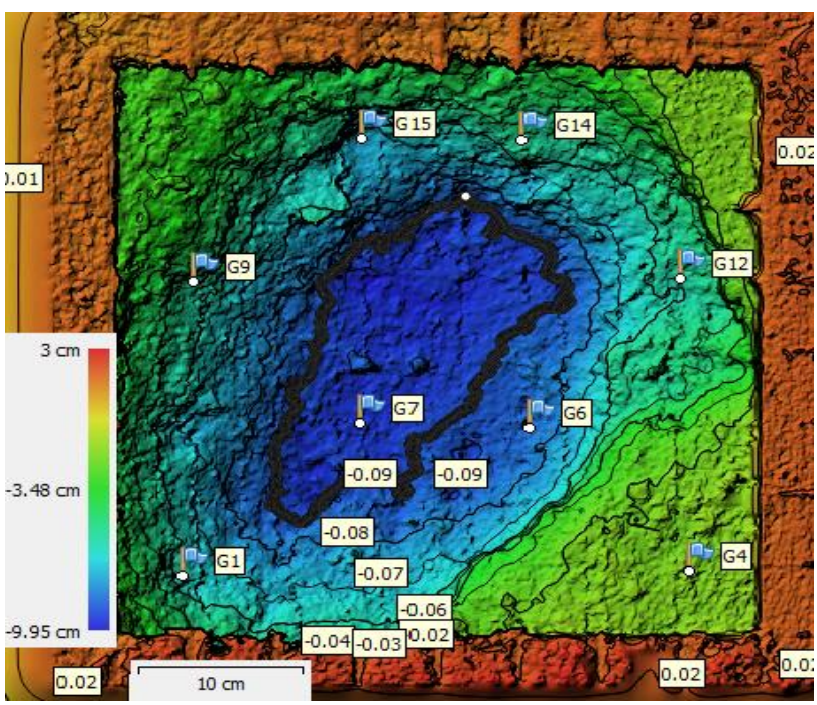

a- DEM extracted from Agisoft PhotoScan.
(Fig. 21) is Counter line surface from Agisoft PhotoScan software matched with orthomosaic and imported by the AutoCAD civil 3-D with 1 $\mathrm{cm}$ counter line interval.

(Fig. 22) shows 3-D model generated with Agisoft PhotoScan software.

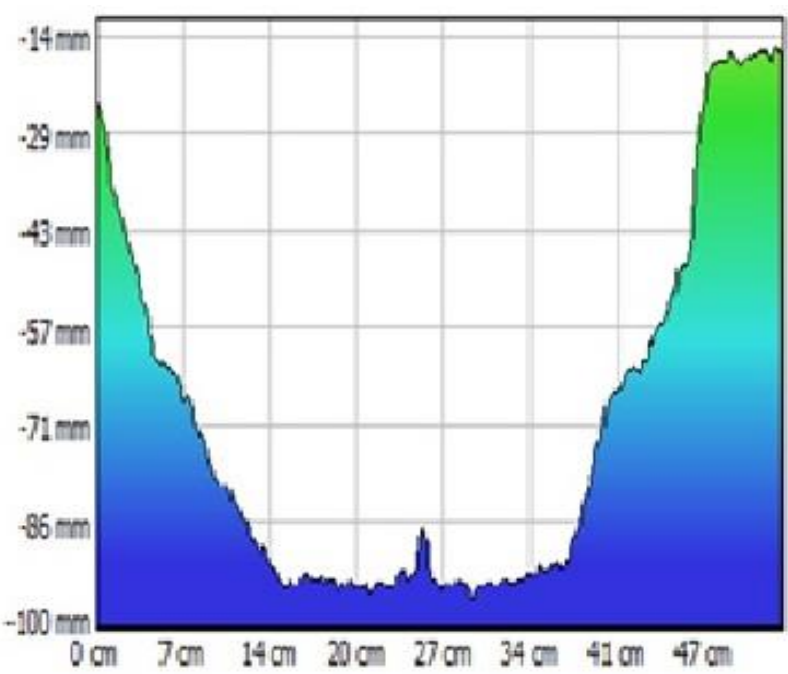

b- Diagonal profile from point $(0,0)$ to $(40,40) \mathrm{cm}$.

Fig. (20): Test two DEM and Profile extracted from Agisoft PhotoScan software. 


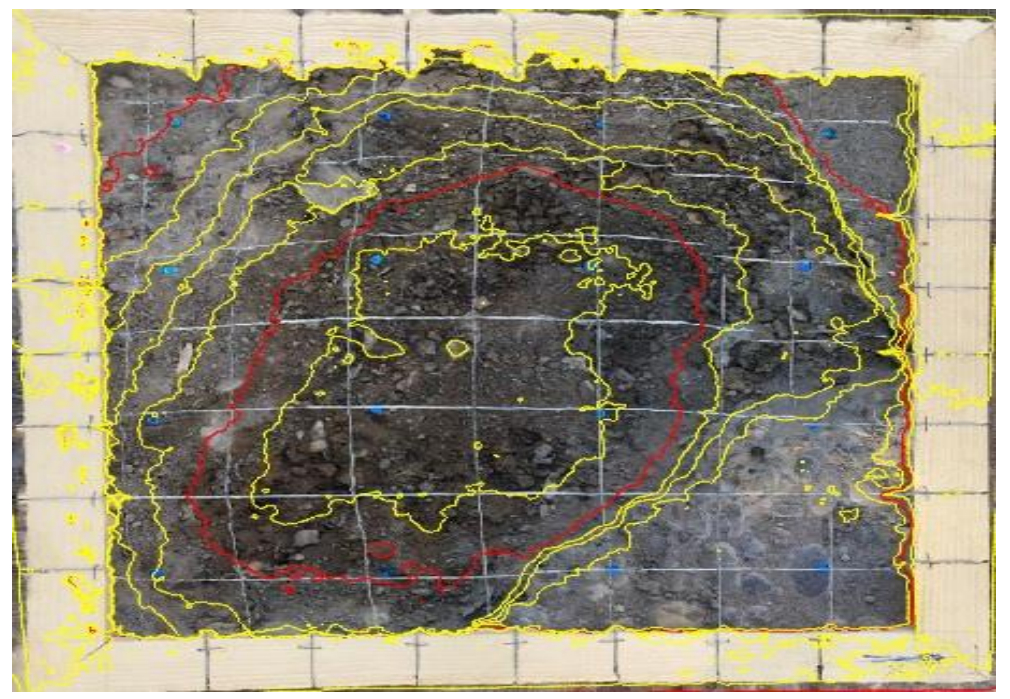

Fig. (21): Test two counter line surface superimposed by orthophoto mosaic

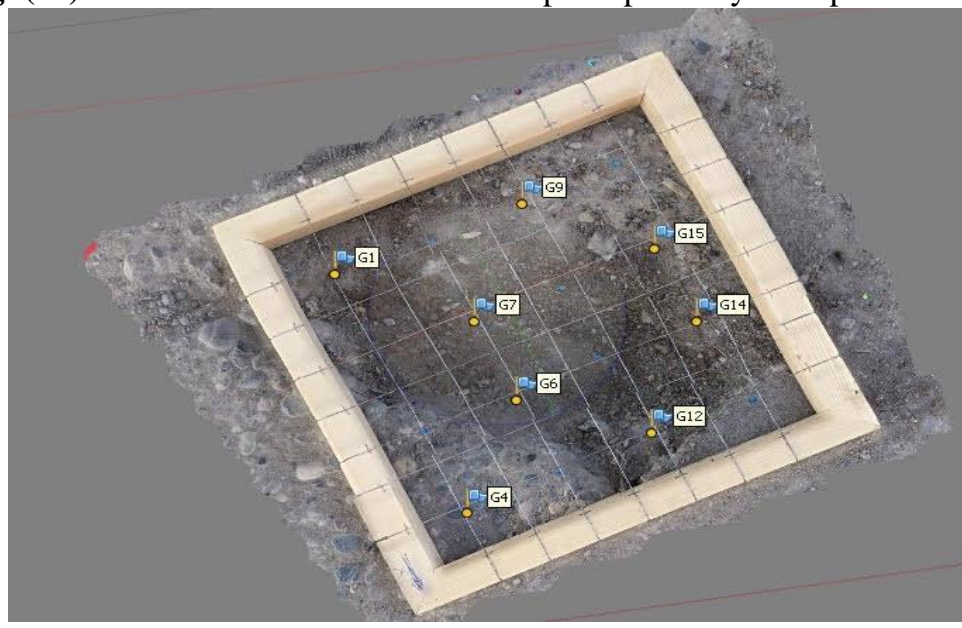

Fig. (22) 3-D model of pothole generated by Agisoft PhotoScan Software.

Table (5): Discrepancy results of test 2 using 2 images with 8 uniformly distributed GCPs. Discrepancy Discrepancy

\begin{tabular}{cccccccc}
\hline Points & $X(\mathrm{~cm})$ & $Y(\mathrm{~cm})$ & $Z(\mathrm{~cm})$ & Points & $X(\mathrm{~cm})$ & $Y(\mathrm{~cm})$ & $Z(\mathrm{~cm})$ \\
\hline $1 C$ & -0.7 & -0.38 & -0.09 & $9 \mathrm{C}$ & -0.07 & 0.04 & -0.08 \\
\hline 2 & 0.09 & -0.57 & -0.11 & 10 & 0.12 & -0.04 & 0.17 \\
\hline 3 & 0.22 & -0.3 & -0.44 & 11 & -0.35 & -0.36 & 0.11 \\
\hline $4 \mathrm{C}$ & 0.04 & 0.05 & -0.91 & $12 \mathrm{C}$ & -0.55 & 0.28 & 0.39 \\
\hline 5 & -0.27 & -0.53 & -0.31 & 13 & 0.28 & 0.05 & -0.63 \\
\hline $6 \mathrm{C}$ & 0.38 & 0.02 & 0.37 & $14 \mathrm{C}$ & -0.11 & -0.11 & -0.33 \\
\hline $7 \mathrm{C}$ & 0.05 & 0.25 & 0.27 & $15 \mathrm{C}$ & 0.24 & -0.13 & -0.14 \\
\hline 8 & -0.55 & -0.22 & -0.13 & 16 & -0.01 & 0.29 & -0.77 \\
\hline & & & & $\sigma$ & \pm 0.32 & \pm 0.27 & \pm 0.39 \\
\hline
\end{tabular}




\section{CONCLUSIONS}

A close-range photogrammetry technique and digital images taken with non-metric cameras are used to make a 3-D model for the distressed areas using the image matching process. One of the challenging tasks in 3-D modelling is the establishing of GCPs in the model space. In this research special control frames were used to measure the local coordinates of every control and checkpoint. The number and distribution of GCPs in the distressed areas have a great effect on the geometrical level of accuracy.

In the Agisoft PhotoScan software assessment test different cases were experimented to obtain the best accuracy for the model. Using 2 images with 3,5, and 7 GCPs clustering on one model side, the accuracy was high in the area surrounding the control points. Far away from the control points the accuracy dropped significantly. When 2 images were used with 8 control points uniformly distributed to cover the shape of the pothole, best accuracy was acquired with a maximum discrepancy of $2.16 \mathrm{~cm}$ in $\mathrm{Z}$ coordinate and standard deviation of $X= \pm 0.79 \mathrm{~cm}, Y= \pm 0.78 \mathrm{~cm}$, and $Z= \pm 0.67$ $\mathrm{cm}$.

In field potholes modeling tests on two sites, higher accuracy was gained on test 2 with a maximum discrepancy of $-0.7 \mathrm{~cm},-0.57 \mathrm{~cm}$, $0.91 \mathrm{~cm}$ in $\mathrm{X}, \mathrm{Y}$, and $\mathrm{Z}$ coordinates respectively and standard deviation of $X= \pm 0.32 \mathrm{~cm}, Y=$ $\pm 0.27 \mathrm{~cm}$, and $\mathrm{Z}= \pm 0.39 \mathrm{~cm}$.

Both of the tested potholes can be classified as high level potholes as their depth exceeds by far $5 \mathrm{~cm}$.

Volume check by sand replacement method with Agisoft generated volume for test one site only shows a $1.2 \%$ difference between both results.

Further work is required to design a special control frame that measures the GCPs quickly and efficiently as fast measurements are required due to the road condition circumstances.

The technique can provide a permanent documentation of the pavement surface distresses, which could be referred whenever needed. For research purposes comparing the model shapes after subjecting the tested area to sever traffic loading and weather conditions could reveal the effects of such conditions with pavement materials on the deterioration of the potholes.

\section{REFERENCES}

Adlinge, S. S., \& Gupta, A. K. (2013). Pavement deterioration and its causes. International Journal of Innovative Research and Development, 2(4), 437-450.

Chai, L.T., 2005. Evaluation of cracks and disintegration using Close Range Digital Photogrammetry and Image Processing Technique (Doctoral dissertation, M. Sc. Thesis, Department of Civil Engineering, College of Engineering, University technology Malaysia).

Clifton Associates Ltd. (2012). Pothole Identification, Assessment and Repair GuidelinesNo Title. Communities of Tomorrow Leveraged Municipal Innovation Fund. https://suma.org/img/uploads/documents/com munities_of_tomorrow/Pothole Guidelines.pdf

Jebur, A., Abed, F., \& Mohammed, M. (2018). Assessing the performance of commercial Agisoft PhotoScan software to deliver reliable data for accurate3D modelling. MATEC Web of Conferences, 162, 3022.

Mustaffara, M., Lingb, T. C., \& Puanb, O. C. (2008). Automated pavement imaging program (APIP) for pavement cracks classification and quantification-a photogrammetric approach. The International Archives of the Photogrammetry, Remote Sensing and Spatial Information Sciences, 37(B4), 367-372.

Oh, J., 2011. Novel approach to epipolar resampling of HRSI and satellite stereo imagery-based georeferencing of aerial images (Doctoral dissertation, The Ohio State University).

Paige-Green, P., Maharaj, A., \& Komba, J. (2010). Potholes: Technical guide to their causes, identification and repair. CSIR Built Environment, Stellenbosch, South Africa.

Perera, R.W., Kohn, S.D. and Tayabji, S.D., 2005. Achieving a high level of smoothness in concrete pavements without sacrificing longterm performance (No. FHWA-HRT-05-068). United States. Federal Highway 
Administration. Office of Infrastructure Research and Development.

quan Li, X., an Chen, Z., ting Zhang, L., \& Jia, D. (2016). Construction and accuracy test of a 3D model of non-metric camera images using Agisoft PhotoScan. Procedia Environmental Sciences, 36, 184-190.

Rutty, G. N. (2008). Essentials of autopsy practice: new advances, trends and developments. Springer Science \& Business Media.

Sarsam, S. I., Daham, A. M., \& Ali, A. M. (2015). Implementation of Close Range Photogrammetry to Evaluate Distresses at Asphalt Pavement Surface. International Journal of Transportation Engineering and Traffic System, 1(1), 1-14.

Shahin, M. Y. (2009). Paver distress identification manual, asphalt surfaced airfields. US Army Corps of Engineers ERDC-CERL, Champaign, IL.
Tan, Y., \& Li, Y. (2019). UAV PhotogrammetryBased 3D Road Distress Detection. ISPRS International Journal of Geo-Information, $8(9), 409$.

Tiong, P. L. Y., Mustaffar, M., \& Hainin, M. R. (2012). Road surface assessment of pothole severity by close range digital photogrammetry method. World Applied Sciences Journal, 19(6), 867-873.

Wang, D., Falchetto, A. C., Goeke, M., Wang, W., Li, T., \& Wistuba, M. P. (2017). Influence of computation algorithm on the accuracy of rut depth measurement. Journal of Traffic and Transportation Engineering (English Edition), 4(2), 156-164.

Wolf, P. R., \& Dewitt, B. A. (2000). Elements of photogrammetry: with applications in GIS (Vol. 3). McGraw-Hill New York. 